\title{
REMOVAL OF HARDLY BIO-DEGRADABALE ORGANIC COMPOUNDS FROM WASTEWATER BY MEANS OF REAGENTLESS METHODS
}

\author{
Joanna Szulżyk-Cieplak \\ 1 Faculty of Fundamentals of Technology, Lublin University of Technology, ul. Nadbystrzycka 38, 20-618 Lublin, \\ Poland, e-mail: j.szulzyk-cieplak@pollub.pl
}

Received: 2017.05.29

Accepted: 2017.08.01

Published: 2017.09.01

\begin{abstract}
The paper discusses the issue of removing persistent organic pollutants (POPs) from wastewater, especially the polycyclic organic hydrocarbons (PAHs). The results obtained in literature studies indicate that the commonly employed traditional methods of wastewater treatment are not always efficient in eliminating the hardly bio-degradable pollutants. Therefore, extensive research is being conducted on the application of efficient POPs removal technologies. One of the considered variants involves incorporating advanced oxidation processes (AOP) into the wastewater treatment systems based on the biological processes. These include the reagentless methods, e.g. the processes involving ultrasounds and hydrodynamic cavitation. On the basis of the author's own studies conducted in a laboratory system comprising a static cavitation reactor, the possibility of applying hydrodynamic cavitation for the decomposition of PAHs was evaluated on the basis of model solutions of anthracene and phenanthrene. It was shown that the employed advanced oxidation process with hydro-cavitation has a significant impact on reducing the concentration of the considered PAHs. It was confirmed that the degradation degree of a substance depends on the intensity and the course of the cavitation process. The energy efficiency of the conducted process was analyzed as well and expressed as the ratio pertaining to the amount of the degraded compound to the electric energy supplied to the system.
\end{abstract}

Keywords: advanced oxidation processes, hydrodynamic cavitation, persistent organic pollutants, polycyclic aromatic hydrocarbons

\section{INTRODUCTION}

Along with the development of civilization and industry, increasing amounts of new and complex chemical compounds are produced and introduced to the natural environment with wastewater, as well as municipal and industrial wastes. These substances are not inert to the living organisms and in majority of cases leave persistent marks. The report concerning chemical pollutants in municipal wastewater and sludge, issued by the European Commission [Final report, ICON, 2001 ], indicates the presence of a great number of compounds which are commonly considered harmful to the human health and lives, including organochlorine pesticides, polychlorinated biphenyls (PCB), phthalates, polycyclic aromatic hydrocarbons, as well as many others, belonging to the groups of so-called persistent organic pollutants. These compounds are toxic, degrade very slowly, and are easily bio-accumulated in the cells of organisms as well as seabed sediments. Despite their low concentrations in the environment, they are considered as highly poisonous, having with carcinogenic, mutagenic, and teratogenic effects [El-Shahawi et al., 2010].

Polycyclic aromatic hydrocarbons constitute the most common xenobiotics found in the natural environment [Srogi, 2007, MaliszewskaKordybach, 2009]. These pollutants, due to their polycyclic structure, are hardly bio-degradable and exert a negative influence on the living organisms [Morrison et al., 1985, Traczewska, 2003]. Uncontrolled discharge of the industrial and 
municipal wastewater as well as leachates from municipal landfills constitutes a major source of surface water pollution. Moreover, a significant amount of PAHs is discharged to the surface recipients along with the treated wastewater and sludge [Countway et al., 2003]. On average, the municipal wastewater contains $1.0 \mu \mathrm{g} / \mathrm{dm}^{3}$ of polycyclic aromatic hydrocarbons [Sánchez-Avila et al., 2009]. The content of PAHs in wastewater varies depending on the type and chemical composition of wastewater, as well as the degree of industrialization characterizing a particular region. Kamińska [Kamińska et al., 2016] showed that the raw wastewater influent to three municipal wastewater treatment plants located in the cities of Silesian agglomeration contain $39 \div 62.2$ $\mu \mathrm{g} / \mathrm{dm}^{3}$ of anthracene and $9.10 \div 15.87 \mu \mathrm{g} / \mathrm{dm}^{3}$ of benzo(a)pyrene. PAHs found in the landfill leachates originate from the materials deposited on the landfill and are also produced in the course of decomposition of the organic matter contained in water. These compounds, which are hardly soluble in water, can relocate because other organic compounds found in leachates act as solvents [Rosik-Dulewska et al., 2009]. The results of studies by Paxeus [Paxeus, 2000] conducted on three old municipal-industrial waste landfills, indicated the presence of 39 potentially hazardous organic substances, including PAHs, such as naphthalene $\left(0.4-400 \mu \mathrm{g} / \mathrm{dm}^{3}\right)$, phenanthrene $\left(0.6-52 \mu \mathrm{g} / \mathrm{dm}^{3}\right)$, fluoranthene $\left(1.0 \div 6.0 \mu \mathrm{g} / \mathrm{dm}^{3}\right)$, pyrene $\left(3.0 \mu \mathrm{g} / \mathrm{dm}^{3}\right)$. Dudzińska and Czerwiński [Dudzińska et al., 2011] presented the results of PAH content in leachates from landfills located in the Lublin Voivodeship. The highest concentrations were found for naphthalene $(52 \div 922$ $\left.\mu \mathrm{g} / \mathrm{dm}^{3}\right)$, phenanthrene $\left(12 \div 85 \mu \mathrm{g} / \mathrm{dm}^{3}\right)$ and anthracene $\left(19 \div 67 \mu \mathrm{g} / \mathrm{dm}^{3}\right)$.

The literature review indicates that the natural processes of PAH decomposition, mainly involving the bacterial and fungal bio-degradation, occur with diversified efficiency [Van Hamme et al. 2003]. The capacity of microorganisms to degrade polycyclic aromatic hydrocarbons depends on the number of rings in the compound. Microorganisms can degrade the compounds with two to four benzene rings. A greater number of rings in a compound make it more resistant to the microbiological "attack". The microbiological decomposition resistance of PAHs results from, among others, the hydrophobic structure of molecules, low solubility in water and thermodynamic stability [Juhasz et al., 2000]. In turn, the chemical oxidation of PAHs mainly leads to the transformations of these compounds and usually does not allow for a total oxidation to $\mathrm{H}_{2} \mathrm{O}$ and $\mathrm{CO}_{2}$. The oxidation products mainly comprise chlorine derivatives (chloro-epoxy-quinones) or halogenated volatile compounds. The oxidized form is usually more toxic. It is believed that the inactive biological forms, such as pyrene, acquire toxic properties under such conditions [Smol et al., 2011]. Ozone constitutes a more efficient and a safer oxidant, ensuring greater degree of PAH removal with much shorter contact time [Beltran, 1995]. However, the products of PAH oxidation with ozone may be toxic and rapidly react with chlorine; therefore, an additional process, e.g. sorption on activated carbon, is recommended [Smol et al., 2011].

Among the physicochemical methods, advanced oxidation processes (AOP) are noteworthy for their high efficiency in degrading hardly bio-degradable compounds. These methods are based on reactions involving highly reactive hydroxyl radicals $\mathrm{OH}^{\bullet}$ generated directly in the reaction system. Various systems are utilized, e.g. chemical processes (electrochemical oxidation with ozone and hydrogen peroxide, Fenton's reaction), photochemical processes (UV photolysis, joint effect of: $\mathrm{UV} / \mathrm{H}_{2} \mathrm{O}_{2}, \mathrm{UV} / \mathrm{O}_{3}, \mathrm{UV} / \mathrm{H}_{2} \mathrm{O}_{2} / \mathrm{O}_{3}$, photo-Fenton reaction), as well as the processes involving ultrasounds and hydrodynamic cavitation. The organic compounds produced in the course of these processes are characterized by a lower molecular mass and greater susceptibility to biodegradation; therefore, they can be efficiently removed by means of the biological methods. Moreover, in contrast to the traditional treatment methods involving separation of pollutants, these methods do not "relocate" pollution problem to another place, but rather lead to the total degradation of harmful substances in the treated wastewater. The results of studies on PAH degradation carried out by means of advanced oxidation processes [Ledakowicz, 2001, Lin et al., 2016] indicate a high degree of reduction of compounds within a very short period of the process duration and the dependence of the degradation degree of particular hydrocarbons on their structure (especially the number aromatic rings in a molecule). The type of the employed AOP method is important as well. In recent years, the phenomenon of cavitation, both the in the ultrasound and hydrodynamic variants, has enjoyed a growing interest in the advanced oxidation processes of pollutants 
found in water and wastewater [Patil et al. 2014, Gogate et al., 2014, Dular et al., 2016, Rajoriya et al., 2016, Tao et al, 2016]. The published research results confirm the high efficiency of applying ultrasound methods for the degradation of polycyclic aromatic hydrocarbons and indicate the dependence of PAHs decomposition on the process parameters and the physicochemical properties of compounds [Psillaki et al., 2004, Sponza et al., 2010, Lin et al., 2016].

Despite numerous advantages, application of advanced oxidation methods for the wastewater treatment on the industrial scale is limited by high technological and operational costs. This problem can be solved by employing the technologies involving hydrodynamic cavitation [Arrojo et al., 2007, Litwinienko et al. 2004, Szulżyk-Cieplak et al., 2013].

\section{MATERIAL AND METHODS}

The aim of the conducted research was to evaluate the possibility of employing hydrodynamic cavitation for the removal of polycyclic compounds from wastewater or landfill leachates. On the basis of model PAH solutions, the impact of the cavitation intensity as well as the process parameters, i.e. the pressure of the system $\left(\mathrm{p}_{0}\right)$ and the circulation degree (Lc) on the degradation of the considered compounds was determined experimentally.

Two polycyclic compounds, i.e. anthracene and phenanthrene, were subjected to laboratory tests. Taking into account that the structures of both compounds are found in carcinogenic polycyclic aromatic hydrocarbons such as benzo(a) pyrene and benzo(a)anthracene, these compounds are used as models in the studies on PAH degradation [Cernigilia et al., 1984]. Additionally, phenanthrene is characterized by the lowest molecular mass among the aromatic hydrocarbons with socalled "bay-region", i.e. the region with increased electron density preventing, for instance, the creation of DNA adducts. Hence, these compounds may influence the cell replication and are considered model compounds in the studies on the metabolism of more complex polycyclic aromatic hydrocarbons [Puglisi et al., 2007]. The research employed the model solutions of phenanthrene (97\%, Fluka Analytical) and anthracene (99\%, Acros Organics) in distilled water, with the concentrations of 5,50 , and $500 \mu \mathrm{g} / \mathrm{dm}^{3}$. The temperature of the solution amounted to $\mathrm{t}=30 \pm 2{ }^{\circ} \mathrm{C}$.

The studies were conducted for the pressure $p_{0}$ in the range $1 \div 7$ bar. This pressure range was selected on the basis of the results of the previous studies conducted by the author (see Table 1), which focused on the impact of process parameters of a hydro-cavitation system, including $p_{0}$ pressure, on the intensity of cavitation, expressed by means of the cavitation number $K(1)$.

It was observed that increasing the input pressure over 7 bar leads to slight changes in the intensity of the cavitation process (similar values of the cavitation number $K$ ); however it also increases the energy expenditures connected with raising the pressure to a given value. Taking these factors into the account, no experiments have been conducted for the inlet pressure higher than 7 bar.

\section{Experimental set-up}

The laboratory stand is presented in Fig. 1. The model PAH solution (anthracene and phenanthrene) was directed by means of a centrifugal pump (2) from the circulation tank (3) to the hydro-cavitation reactor (1), and subsequently redirected back to the tank (3).

The main part of the test stand is the cavitation reactor (Fig. 2). A cavitation reactor of the static type, built according to the original author's design, was used in the research. In the reactor, cavitation is generated as a result of a special element, so-called cavitation inductor (5). Replaceable plates are used for that purpose. A plate with ten cylindrical orifices ( $2 \mathrm{~mm}$ in diameter) distributed evenly over the circumference and plate axis was employed in the study. The cavitation chamber $(2,6)$ is characterized by a circular in cross-section and is made of organic glass, which enables to observe the creation and dissipation of cavitation bubbles in the flow.

Table 1. Characteristics of the cavitation process intensity with variable pressure values

\begin{tabular}{|l|c|c|c|c|c|c|c|c|c|c|}
\hline $\begin{array}{l}\text { Pressure } p_{0} \\
\text { [bar] }\end{array}$ & 1 & 2 & 3 & 4 & 5 & 6 & 7 & 8 & 9 & 10 \\
\hline $\begin{array}{l}\text { Cavitation } \\
\text { number } K\end{array}$ & 2.4358 & 1.4255 & 0.9112 & 0.9112 & 0.4449 & 0.3768 & 0.3202 & 0.2945 & 0.2695 & 0.2475 \\
\hline
\end{tabular}




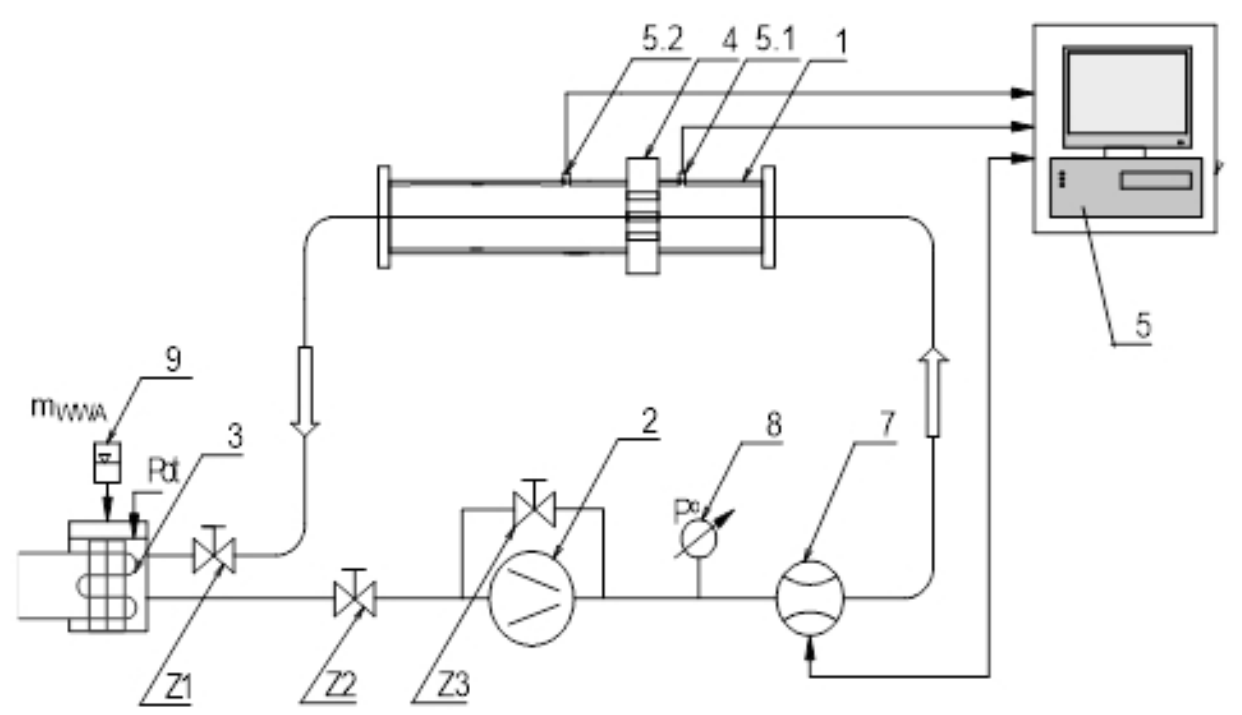

Figure 1. Scheme of the test stand. 1 - cavitation reactor, 2 - Wilo type MVIE 208-2G/PNIG centrifugal pump, 3 - circulation tank with cooling element, 4 - cavitation inductor, 5 - computer system of measurement data collection and processing, 5.1 and 5.2 - pressure sensors, 7 - electromagnetic flow meter, Z1 - regulation valve, Z2 - cut-off valve, Z3 - pump overflow valve, 8 - spring manometer, 9 - PAH injector

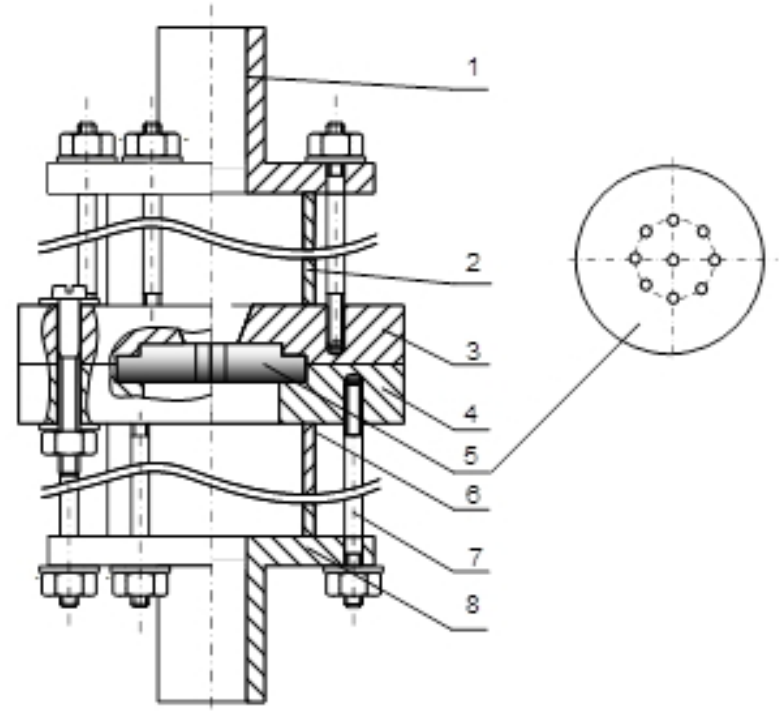

Figure 2. Scheme of the designer cavitation reactor: 1, 8 - inlets, 2, 6- housing made of organic glass, 3,4 - steel plates connecting the housing, 5 - cavitation inductor, 7 - pins connecting the housing of the cavitation reactor

\section{Intensity of cavitation}

Intensity of cavitation constitutes a value which can be used to quantitatively measure the status of cavitation. It can be described by means of cavitation index $K$ :

$$
K=\frac{p-p_{n}}{(1 / 2) \cdot \rho \cdot w^{2}}
$$

where: $\mathrm{p}$ - pressure in the undisturbed flow [Pa], $\mathrm{p}_{\mathrm{n}}-$ vapour pressure $[\mathrm{Pa}]$, $\rho$ - liquid density $\left[\mathrm{kg} / \mathrm{m}^{3}\right]$, $\mathrm{w}-$ velocity of the liquid flowing through the cavitation inductor $[\mathrm{m} / \mathrm{s}]$.

\section{Assessment of process efficiency}

The efficiency of hydrodynamic decomposition process of the examined substances was assessed in terms of changes in the concentration of anthracene and phenanthrene in relation to their initial concentration, according to the following formula: 


$$
\zeta=\frac{C_{0}-C_{\tau}}{C_{0}}
$$

where: $\mathrm{C}_{0}$ - initial concentration of a solution $\left[\mu \mathrm{g} / \mathrm{dm}^{3}\right]$,

$\mathrm{C}_{1}$ - concentration of a solution after the period $\tau$ of the cavitation process $\left[\mu \mathrm{g} / \mathrm{dm}^{3}\right]$

The efficiency of compounds degradation in a hydro-cavitation system is dependent on the circulation degree (number of repetitions during processing). Achieving the desired degradation effect is usually connected with repeating the flow of the considered solution through the cavitation zone multiple times. Increasing the circulation degree involves higher energy expenditures; therefore, it is essential to adjust the system operation parameters so that the energy consumption is as low as possible. The following relation was used to determine the circulation degree:

$$
L_{c}=\tau \cdot \frac{V}{v_{u}}
$$

where: $\tau$-duration of the cavitation [s],

$\dot{V}$-volumetric flow rate $\left[\mathrm{m}^{3} / \mathrm{s}\right]$,

$V_{u}$ - volume of the experimental system $\left[\mathrm{m}^{3}\right]$.

The energy efficiency of the process constitutes an important parameter, which is directly reflected in the costs of the treatment process. The amount of energy consumed for degradation of anthracene and phenanthrene was assessed by assuming two types of energy efficiency, i.e. $Y_{e l}$ and $Y_{c}$. The energy efficiency $Y_{e l}$ pertains to the actual amount of electricity taken from the grid in relation to the amount (expressed in $\mathrm{mg}$ ) of the degraded compound. On the other hand, the energy efficiency $Y_{c}$ (5) determines the ratio of the energy supplied to the liquid to the amount of removed compound.

$$
Y_{e l}=\frac{X_{\tau}}{P \cdot \tau} \quad[\mu \mathrm{g} / \mathrm{J}]
$$

where : $X_{\tau}-$ loss of PAHs after the period of $\tau$ $[\mu \mathrm{g}]$,

$P$ - active power used by the pump [W], $\tau-$ duration of the cavitation process [s],

$$
Y_{c}=\frac{X_{\tau}}{H \cdot \rho \cdot g \cdot V \cdot \tau} \quad[\mu \mathrm{g} / \mathrm{J}]
$$

where: $X_{\tau}$ - loss of PAHs after the period of $\tau$ $[\mu \mathrm{g}]$,

$H$-head [m], $\rho$ - density of the liquid $\left[\mathrm{kg} / \mathrm{m}^{3}\right]$,
$g$ - gravitational acceleration $\left[\mathrm{m} / \mathrm{s}^{2}\right]$,
$V$ - volumetric flow rate $\left[\mathrm{m}^{3} / \mathrm{s}\right]$,
$\tau$ - duration of the cavitation process $[\mathrm{s}]$

\section{RESULTS AND DISCUSSION}

The obtained research results confirmed the existence of physicochemical cavitation effects, which were observed as changes in the concentration of anthracene and phenanthrene in the model solutions. An exemplary chromatogram from the analysis of the considered PAHs is shown in Figure 3. Simultaneously, it was noted that under constant conditions of the process (input pressure, temperature of the solution, circulation degree), the degradation of phenanthrene is slightly greater $(3 \div 8 \%$, depending on the initial concentration of the solution $C_{0}$ ) than in the case of anthracene (Fig. 3, 4). This is connected with the symmetrical structure of anthracene (linear), which gives it greater energy stability and thus makes the degradation more difficult.

In order to evaluate the impact of the initial concentration $C_{0}$ of anthracene and phenanthrene on the degradation degree of compounds, studies were conducted in a hydro-cavitation system with constant process parameters for the initial concentration values of $C_{0}=5,50$ and $500 \mu \mathrm{g} /$ $\mathrm{dm}^{3}$. The dependency of the degradation degree on the initial concentration value $C_{0}$ (see Fig. 4) of the examined compounds was observed, which correlates with the results obtained by Psillakis et al. [2004]. The degradation degree of anthracene and phenanthrene increases as the initial concentration of the model solution drops. In the case of the concentrations $C_{0}=5$ and $50 \mu \mathrm{g} / \mathrm{dm}^{3}$, the degradation efficiency of the compounds is very similar. For the circulation degree $L c=1$, the changes in anthracene concentration for both values of initial concentration reached $79 \%$, whereas in the case of phenanthrene $-83 \% C_{0}=5 \mu \mathrm{g} / \mathrm{dm}^{3}$ for and $82 \%$ for $C_{0}=50 \mu \mathrm{g} / \mathrm{dm}^{3}$. A significantly lower degradation efficiency was obtained with the concentration of $C_{0}=500 \mu \mathrm{g} / \mathrm{dm}^{3}$ (8 \% for anthracene and $13 \%$ for phenanthrene).

Polycyclic aromatic hydrocarbons in wastewater/landfill leachates are found in trace amounts. The obtained research results indicate that due to a high efficiency of anthracene and phenanthrene degradation at low initial concentrations of the model solutions, the hydro-dynamic cavitation 


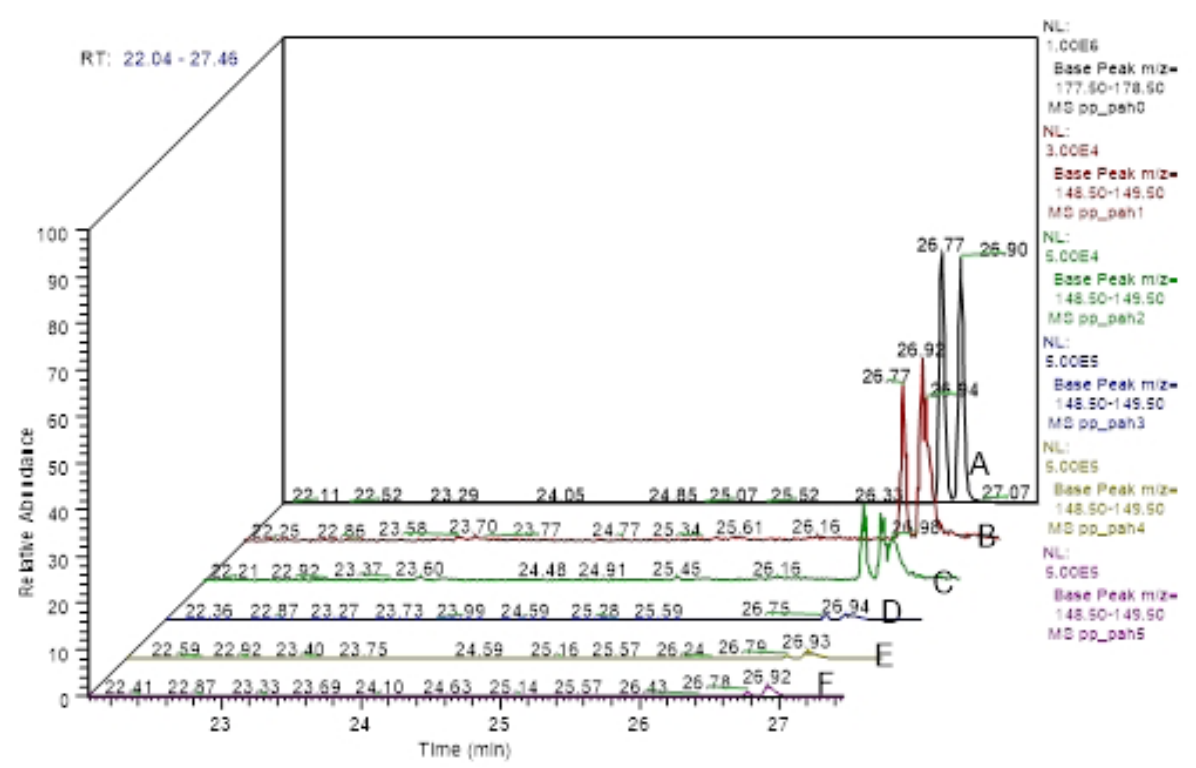

Figure 3. Degradation of phenanthrene and anthracene after $\mathrm{A}-1, \mathrm{~B}-2, \mathrm{C}-4, \mathrm{D}-10, \mathrm{E}-20$ and $\mathrm{F}-30$ min of cavitation

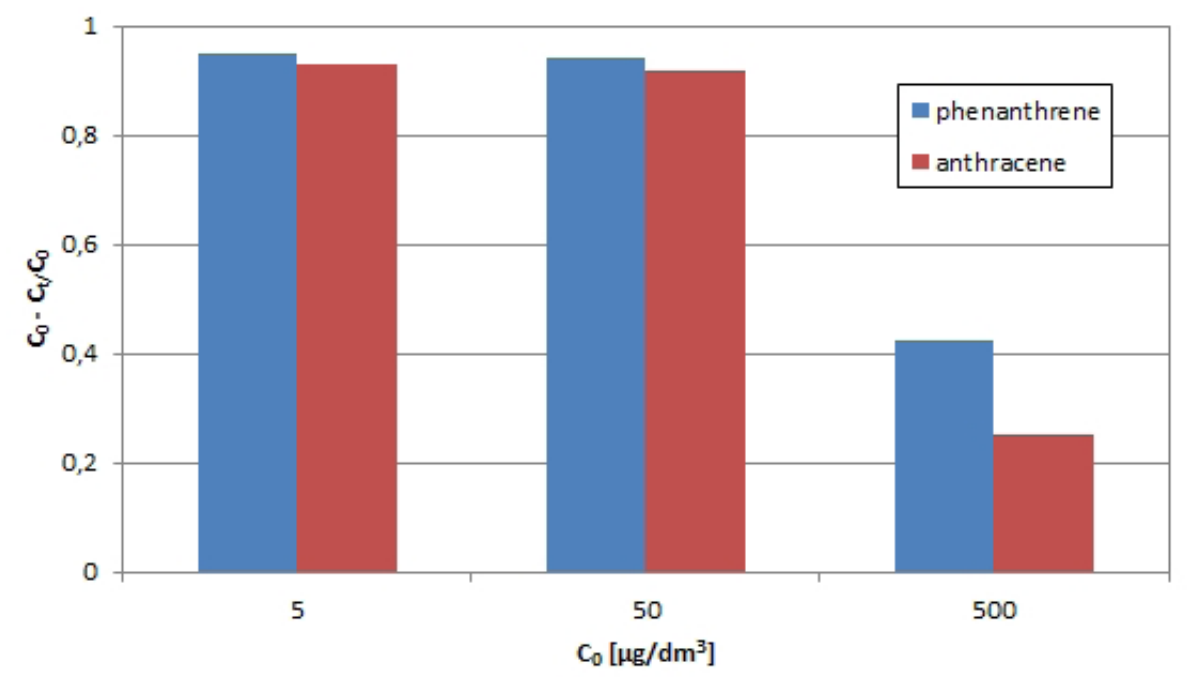

Figure 4. Degradation degree of anthracene and phenanthrene for a single run through the cavitation zone, depending on the initial concentration of the solution $C_{0}$, inductor $3, p_{0}=7 \mathrm{bar}, \mathrm{t}=30 \pm 2{ }^{\circ} \mathrm{C}$

constitutes a promising method of degrading PAH compounds in the aquatic environment.

The following step of the experimental works involved conducting studies on the degradation degree of anthracene and phenanthrene depending on the inlet pressure $p_{0}$. The obtained results prove that in the considered $p_{0}$ pressure range 1-7 bar, the degradation degree of both compounds increases along with the raise of the inlet pressure, which is illustrated with an exemplary graph of anthracene degradation (see Fig. 5).

When the solution was ran through the system 10 times, $(\mathrm{Lc}=10)$ the degradation degree reached $86 \%$ with the pressure $p_{0}=3$ bar and $96 \%$ in the case of $p_{0}=7$ bar. No changes in the concentration of the compounds during the cavitation process were observed for the pressures $p_{0}=$ 1 bar and $p_{0}=2$ bar (hence, the lack of data on the graph), which can be explained by analyzing the data presented in Table 1. Under the pressure of $p_{0}=2$ bar, the cavitation number amounts to $K=$ 1.4255 and rapidly increases as the inlet pressure drops. As indicated by the literature data [Kanthale et al., 2005, Arrojo et al., 2008], cavitation does not occur for the number of cavitation $\mathrm{K}>1$.

As it was mentioned earlier, the value of inlet pressure $p_{0}$ strictly depends on the course and intensity of the cavitation process. The influence of 


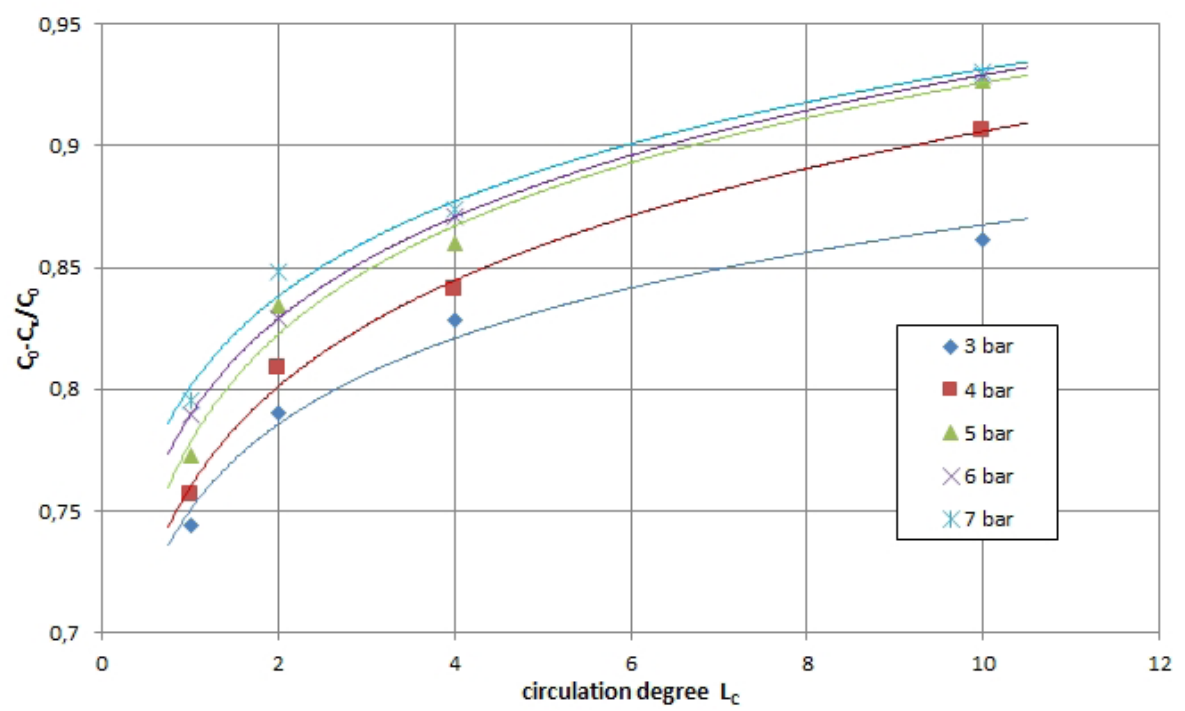

Figure 5. Changes in the degradation degree of anthracene depending on the circulation degree $L c$ and variable inlet pressure values $p_{0}$.

cavitation number $K$ on the changes of the degradation degree of anthracene and phenanthrene in relation to a single run was presented in Figure 6.

Taking into account that the increase of inlet pressure of the system reduces the cavitation number (greater intensity), this indicates a strict relationship between the intensity of cavitation and the degradation degree of compounds.

As far as the economical factor is concerned, the impact of inlet pressure on the energy efficiency of anthracene and phenanthrene degradation was analyzed. The graph (Fig. 7) presents the relation of energy efficiency values $Y_{e l}$ and $Y_{c}$ to the pressure range $3 \div 7$ bar in a single run of the solution - characterized by the concentration $C_{0}=50 \mu \mathrm{g} / \mathrm{dm}^{3}$ - through the hydro-cavitation system.

The conducted studies show that along with the inlet pressure increase, the energy efficiency $Y_{e l}$ drops. Electric power required to create a desired pressure in the system grows along with $p_{0}$, which translates into a decrease of energy efficiency $Y_{e l}$. On the other hand, in the case of the efficiency $Y$, an increase is observed along with the growth of pressure $\left(p_{0}\right)$. The energy efficiency of the system increases together with the inlet pressure, simultaneously boosting the useful energy.

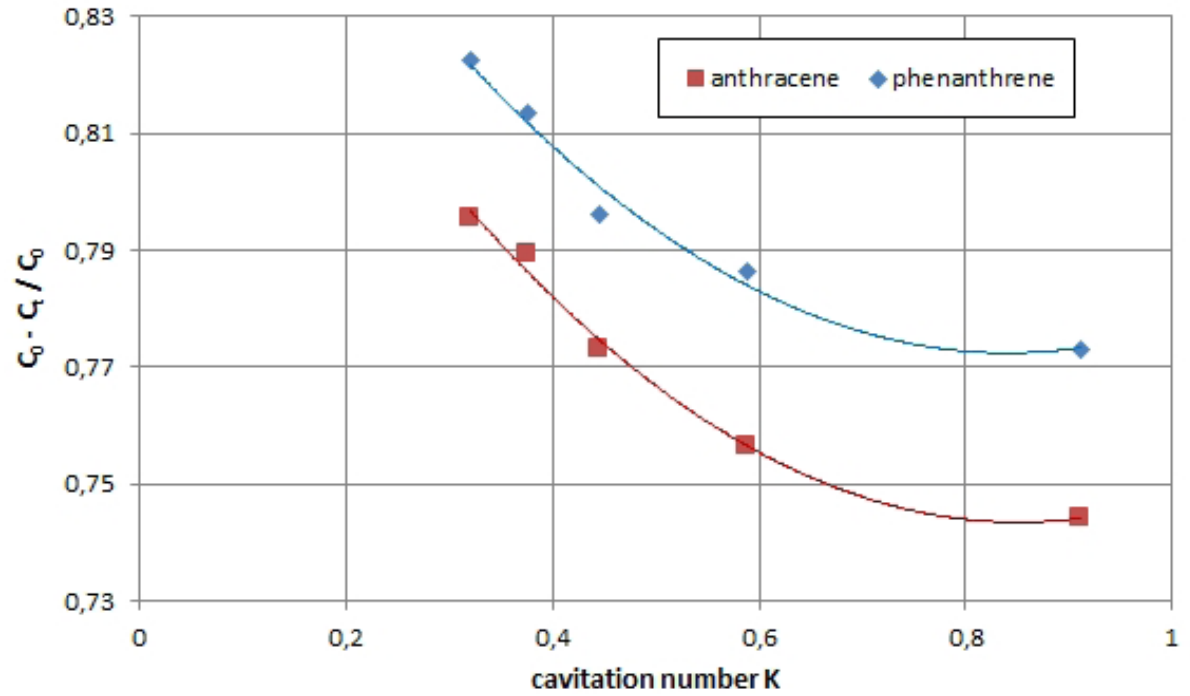

Figure 6. Degradation degree of anthracene and phenanthrene for a single run through the cavitation zone depending on the cavitation number $K, \mathrm{t}=30 \pm 2{ }^{\circ} \mathrm{C}, C_{0}=50 \mu \mathrm{g} / \mathrm{dm}^{3}$ 


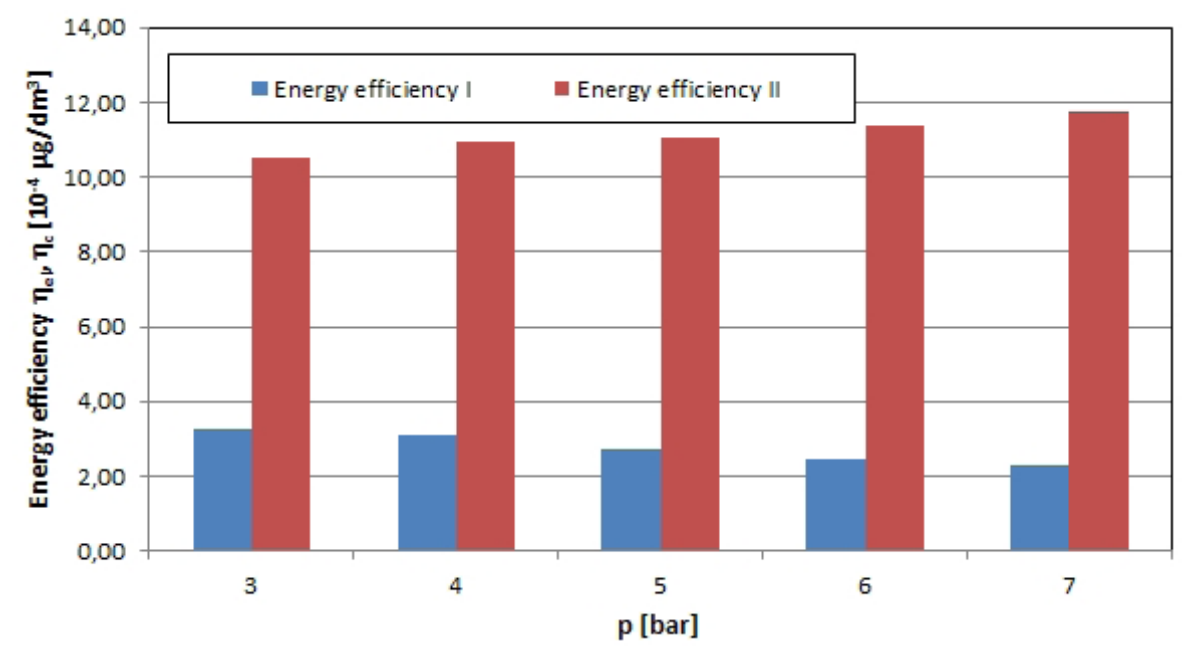

Figure 7. Energy efficiency $Y_{e l}$ (I) and $Y_{c}$ (II) of phenanthrene degradation in a hydro-cavitation system for variable inlet pressure values $p_{0}, L_{C}=1, \mathrm{t}=30 \pm 2{ }^{\circ} \mathrm{C}, C_{0}=50 \mathrm{mg} / \mathrm{dm}^{3}$

\section{CONCLUSIONS}

The possibility of employing hydrodynamic cavitation in the treatment of water containing hardly-biodegradable compounds was analyzed in the paper. The conducted laboratory research indicates that the phenomenon of hydrodynamic cavitation enables a significant reduction of anthracene and phenanthrene concentrations in the model water solutions. The phenomenon of hydrodynamic cavitation seems to be a novel, advanced technology for the degradation of complex compounds and constitutes an alternative to other advanced oxidation processes. Following conclusions can be drawn from the conducted studies:

1. The phenomenon of hydrodynamic cavitation is an efficient process enabling to decrease the concentrations of anthracene and phenanthrene in the model water solutions.

2. The degradation degree of the considered compounds depends on the parameters of the cavitation process and is strictly connected with the intensity of the phenomenon.

3. Introducing the value $Y_{e l}$ for the assessment of energy efficiency characterizing the process enables an easy estimation of energy expenditures necessary for conducting the cavitation process, which may prove useful in designing the processing line for the degradation of organic pollutants, including polycyclic aromatic hydrocarbons.

\section{REFERENCES}

1. ICON Consultants. Pollutants in Urban Waste Water and Sewage Sludge - Final Report for DG Research, 2001, Office for Official Publications of the European Communities: Luxembourg.

2. El-Shahawi M.S., Hamza A., Bashammakh A.S., Al-Saggaf W.T. 2010, An overview on the accumulation, distribution, transformations, toxicity and analytical methods for the monitoring of persistent organic pollutants, Talanta 80, 1587-1597.

3. Srogi K., 2007, Monitoring of environmental exposure to polycyclic aromatic hydrocarbons: a review, Environmental Chemistry Letters, 5, 169-195.

4. Maliszewska-Kordybach B., Smreczak B., Klimkowicz-Pawlas A., 2009, Concentrations, sources, and spatial distribution of individual polycyclic aromatic hydrocarbons (PAHs) in agricultural soils in the Eastern part of the EU : Poland as a case study, Science of the Total Environment, 407, 3746-3753.

5. Morrison R.T., Boyd R.N., 1985, Organic Chemistry Vol 2 (in Polish), Państwowe Wydawnictwo Naukowe, Warszawa.

6. Traczewska T., 2003, Biotoxicity of products of transformation of anthracene and phenanthrene in water as well as their possible removal (in Polish), Oficyna Wydawnicza Politechniki Wrocławskiej, Wrocław.

7. Countway R., Dickhut R., Canuel E., 2003, Polycyclic aromatic hydrocarbon (AH) distribution and association with organic matter in surface waters of the York River, VA Estuary, Organic Geochemistry, 34, 209-224.

8. Sanchez-Avila J., Bonet J., Velasco G, Lacorte S. 2009, Determination and occurrence of phthal- 
ates, alkylphenols, bisphenol A, PBDEs, PCBs and PAHs in an industrial sewage grid discharging to a Municipal Wastewater Treatment Plant. Science of The Total Environment 407 (13), 4157-4167.

9. Kamińska, G. Kudlek, E. Dudziak, M. Bohdziewicz, J. 2016, Removal of biologically active substances during mechanical-biological wastewater treatment (in Polish), Inżynieria Ekologiczna, 50, 201-209.

10. Rosik-Dulewska Cz., Karwaczyńska U., Ciesielczuk T., 2009, Migration of PAHs from unsealed landfill to groundwaters (in Polish), Rocznik Ochrony Środowiska, Wydawnictwo ŚrodowoPomorskiego Towarzystwa Naukowego Ochrony Środowiska, 9, 335-345.

11. Paxus N. 2000, Organic Compounds in Municipal Landfill Leachates, Water Science \& Technology, 42.7-8, 323-33.

12. Dudzińska M., Czerwiński J., 2011, Persistent Organic Pollutants (POPs) in leachates from municipal landfills, Int. J. Environmental Engineering, 3, 253-268.

13. Van Hamme J., Owen W., Singh A., 2003, Accelerated biodegradation of petroleum hydrocarbon waste, Journal of Industrial Microbiology and Biotechnology, 30, 260-270.

14. Juhasz A., Naidu R. 2000, Bioremediation of high molecular weight polycyclic aromatic hydrocarbons: a review of the microbial degradation of benzo[a]pyrene, International Biodeterioration \& Biodegradation, 45, 57-88.

15. Smol M., Włodarczyk-Makuła M., 2011, Removal of PAHs from wastewater in the physical and chemical processes (in Polish), Zeszyty Naukowe. Inżynieria Środowiska/ Uniwersytet Zielonogórski, 141(21), 87 - 97.

16. Beltran F.J., Ovejero G., Garcia-Araya J., Rivas J. 1995, Oxidation of Polynuclear Aromatic Hydrocarbons in Water. 2. UV Radiation and Ozonation in the Presence of UV Radiation, Industrial \& Engineering Chemistry Research, 34(5), 1607-1615.

17. Lin M., Ning X., An T. 2016, Degradation of polycyclic aromatic hydrocarbons (PAHs) in textile dyeing sludge with ultra-sound and Fenton processes: Effect of system parameters and synergistic effect study, Journal of Hazardous Materials, 307, 7-16.

18. Ledakowicz S., Miller J., Olejnik D., 2001, Oxidation of PAHs in water solution by ozone combined with ultrafiolet radiation, International Journal of Photoenergy, 3, 95-101.

19. Tao Y., Cai J., Huai X. 2016, Application of Hydrodynamic Cavitation to Wastewater Treatment, Chemical Engineering \& Technology, 39(8), 1363-1376.

20. Rajoriya S., Carpenter J., Saharan, V.K. 2016, Hydrodynamic cavitation: an advanced oxidation process for the degradation of bio-refractory pollutants, Reviews in Chemical Engineering, 32(4), 379-411.
21. Dular M., Griessler-Bulc T., Gutierrez-Aguirre I. 2016, Use of hydrodynamic cavitation in (waste) water treatment, Ultrasonics Sonochemistry, 29, 577-588.

22. Gogate P.R., Patil P.N. 2015, Combined treatment technology based on synergism between hydrodynamic cavitation and advanced oxidation processes, Ultrasonics Sonochemistry, 25, 60-69.

23. Patil A.L., Patil P.N., Gogate P.R. 2014, Degradation of imidacloprid containing wastewaters using ultrasound based treatment strategies, Ultrasonics Sonochemistry, 21(5), 1778-1786.

24. Psillakis E., Goula G., Kalogerakis N., Mantzavinos D., 2004, Degradation of polycyclic aromatic hydrocarbons in aqueous solutions by ultrasonic irradiation, Journal of Hazardous Materials, B108, 95-102.

25. Sponza D.T., Oztekin R., 2010, Removals of PAHs and acute toxicity via sonication in a petrochemical industry wastewater, Chemical Engineering Journal, 162, 142-150.

26. Arrojo S., Neron C., Benito Y., 2007, Application of salicylic acid dosimetry to evaluate hydrodynamic cavitation as an advanced oxidation process, Ultrasonics Sonochemistry, 14, 343-349.

27. Litvinienko A., Nekroz A., Łukasik K., 2005, Technological application of hydrodynamic cavitation - experiences and perspectives (in Polish), Lubelskie Towarzystwo Naukowe, Lublin.

28. Szulzyk-Cieplak J., Ozonek J. 2013, Research on Impact of Selected Parameters of Hydrodynamic Cavitation System on the Anthracene and Phenanthrene Degradation Degree in the Cavitating Liquid Environment, Rocznik Ochrona Srodowiska, $15,996-1010$.

29. Szulzyk-Cieplak J., Ozonek J. 2013, Study of the process of phenanthrene degradation in a cavitated liquid environment, Chemik, 67(10), 1003-1010.

30. Cerniglia CE. 1984, Microbial metabolism of polycyclic aromatic hydrocarbons, Adv Appl Microbiol., 30, 31-71.

31. Puglisi E., Cappa F., Fragoulis G., Trevisan M., 2007, Bioavalibility and degradation of phenanthrene In kompost amended soils, Chemposphere, 67, 548-556.

32. Psillakis E., Goula G., Kalogerakis N., Mantzavinos D., 2004, Degradation of polycyclic aromatic hydrocarbons in aqueous solutions by ultrasonic irradiation, Journal of Hazardous Materials, B108, 95-102.

33. Kanthale P.M., Gogate P.R., Pandit A.B., Wilhelm A.M., 2005, Dynamics of cavitational bubbles and design of a hydrodynamic cavitational reactor: cluster approach, Ultrasonics Sonochemistry, 12, 441-452.

34. Arrojo S., Benito Y., 2008, A theoretical study of hydrodynamic cavitation, Ultrasonics Sonochemistry, 15, 203-211. 